\title{
ANTIOXIDANT ACTIVITY OF INSECT GALL EXTRACTS OF PISTACIA INTEGERRIMA
}

\author{
Ravi Shankara Birur Eshwarappa ${ }^{1,2,3 凶}$, Ramachandra Yarappa Lakshmikantha, \\ Sundara Rajan Subaramaihha², Sujan Ganapathy Pasura Subbaiah², \\ Austin Richard Surendranath ${ }^{4}$, Bhadrapura Lakkappa Dhananjaya ${ }^{5 \bowtie}$ \\ ${ }^{1}$ Department of Chemistry, School of Graduate Studies, Jain University \\ Bangalore - 560002, India \\ ${ }^{2}$ Research Unit in Vrukshayurveda, A Division of Centre for Advanced Studies in Biosciences, Jain University \\ Chamrajpete, Bangalore - 560019, India \\ ${ }^{3} \mathrm{PG}$ Department of Studies and Research in Biotechnology, Kuvempu University \\ Shankarghatta - 577451, Karnataka, India \\ ${ }^{4}$ Department of Biochemistry, University of Mysore \\ Mysore - 570006, Karnataka, India \\ ${ }^{5}$ Toxinology/Toxicology and Drug Discovery Unit, Center for Emerging Technologies (CET), Jain University \\ Kanakpura Taluk, Ramanagara - 562112, India
}

\begin{abstract}
Background. Pistacia integerrima (P. integerrina) insect galls are widely used in ayurveda and siddha system of medicine as karkatasringi. The use of leaf galls as a rejuvenator may be attributed to antioxidant property, however there is less scientific evidence. Therefore, the aim of this study was to evaluate the chemical composition and the antioxidant potential of leaf gall extracts (aqueous and ethanol) of $P$. integerrina, which is extensively used in the preparation of traditional medications.

Material and methods. The antioxidant activities of aqueous and ethanolic leaf gall extracts were examined using diphenylpicrylhydrazyl (DPPH), hydroxyl scavenging and ferric reducing power (FRAP) methods.

Results. The presences of phenolics, tannins, phytosterols, triterpenoids, saponins, flavonoids and reducing sugars were identified in both the extracts. In comparison to the aqueous extract, the ethanolic extract had the highest total phenolic and flavonoid content at $234 \pm 2.4 \mathrm{mg}$ of GAE/g d.w. and $95.5 \pm 3.2 \mathrm{mg}$ of QUE/g d.w., respectively. This higher content of total phenolics and flavonoids found in the ethanolic extract was directly associated with higher antioxidant activity.

Conclusion. This study demonstrates the poetnet antioxidant activities of $P$. integerrima leaf gall extracts. Further, there was a strong association between the higher antioxidant activities with that of higher total phenolic and flavonoid content in the ethanolic leaf gall extracts of $P$. integerrima. The results encourage the use of $P$. integerrima leaf gall extracts for medicinal health, functional food and nutraceuticals applications, due to their antioxidant properties. Future work will be interesting to learn the chemical composition and better understand the mechanism of action of the antioxidants present in the extract for development as a drug for therapeutic application.
\end{abstract}

Key words: free radicals, plants, galls, antioxidant, ethnobotanical, polyphenols 


\section{INTRODUCTION}

Reactive oxygen species (ROS) are highly active oxygen species, generated as natural by-products of normal oxygen consuming metabolic process in the body. Any imbalance between the antioxidant defense and the formation of ROS, can lead the system into oxidative stress. It is well established that free radicals are very much implicated in several metabolic diseases that include heart diseases, acquired immunodeficiency syndrome, diabetes mellitus, arthritis, cancer, ageing, liver disorder etc. (Halliwell, 1997), and the antioxidant therapy has gained an utmost importance in the treatment of these diseases (Eshwarappa et al., 2015). The World Health Organization estimates that $80 \%$ of the world's population use herbal medicines in some aspects of primary healthcare (Gossell-Williams et al., 2006). In these aspects, all round the world, the medicinal properties of plants have been investigated and explored for their potent antioxidant activities to counteract metabolic disorders, that are with no side effects and with high economic viability (Auddy et al., 2003; Shrestha et al., 2013, 2014).

Pistacia integerrima (family anacardiacea) is a multi-branched, single stem moderate-sized deciduous tree, found in eastern Himalayan range from Indus to Kumaon. The insect galls produced on the leaves and petioles are widely used in ayurveda and the Siddha system of medicine as "Karkatasringi" (Shrestha et al., 2013; Eshwarappa et al., 2014; Eshwarappa et al., 2015; CSIR, 1976; Shantha et al., 1991; Kottakkal, 1995). Karkatasringi has been used as an ingredient in many ayurvedic preparations like dasamularista, chyavanaprasa and singyadichurna etc. which are used in treating various diseases like asthma, tuberculosis, indigestion, liver disorders and other ailments (Shrestha et al., 2013; Eshwarappa et al., 2014; Eshwarappa et al., 2015; CSIR, 1976; Shantha et al., 1991; Kottakkal, 1995). They are also used in the Siddha system of medicine to treat diarrhea, dysentery and bronchial asthma (Shrestha et al., 2013; CSIR, 1976; Shantha et al., 1991; Kottakkal, 1995; Shrestha et al., 2013; Eshwarappa et al., 2014; Eshwarappa et al., 2015). Karkatshringi also finds usage in the treatment of children's ear infections, suppress hemorrhage from gums and used to suppress bleeding from nose (Kirthikar and Basu, 1935; Sukh, 1997; Shrestha et al., 2013; Shrestha et al., 2014; Eshwarappa et al., 2014; Eshwarappa et al., 2015). Hakims consider galls useful in pulmonary infections, diarrhea and vomiting (Nadkarni, 1976; Eshwarappa et al., 2014; Eshwarappa et al., 2015). Galls are also used in some of the ayurvedic formulations like 'Kumari Asava' and 'Kumari Kalp' etc. and prescribed for weakness as rejuvenating agent and tonic (Gunakari Ayurvediy..., 1968; Eshwarappa et al., 2014; Eshwarappa et al., 2015). Gall extracts are known to have expectorant, bronchodilator, antiemetic, appetizer, diuretic and antirheumatic effects (Eshwarappa et al., 2014; Eshwarappa et al., 2015). It has been used in nose bleeding, snake bite and scorpion sting effects in folk medicine (Eshwarappa et al., 2014; Eshwarappa et al., 2015). The use of leaf galls as a rejuvenator may be attributed to antioxidant properties (Eshwarappa et al., 2014; Eshwarappa et al., 2015). Tannins, flavonoids, monoterpenes, triterpenoids, sterol, dihydromalvalic acid, flavonoids, essential oils, anthocyanins and other phenolic constituents have been reported from the different parts of Pistacia species (Ahmed et al., 2010, 2011; Bozorgi et al., 2013). Phenolics, Fatty ester, ketoalcohol and triterpenic acid have been reported from galls of P. integerrima (Ahmed et al., 2010, 2011). These all chemical constituents might be responsible for the antioxiand activities, however there are no scienfific evaluation done in support. Therefore the aim of this study was to investigate the antioxidant potential of aqueous and ethanol extracts of insect gall of $P$. integerrima by assessing the total phenolic and flavonoid contents, as well as DPPH, hydroxyl radical scavenging activities, and FRAPS potential in support of its antioxidant activities.

\section{MATERIAL AND METHODS}

\section{Materials}

Folin-Ciocalteu reagent and quercetin were obtained from Qualigens, Mumbai, India. Ascorbic acid, Gallic acid, Quercetin, L-ascorbic acid, potassium thiocyanate, ethylene diamine tetra acetic acid (EDTA), 2,2-diphenyl1-picrylhydrazyl (DPPH), 2-deoxyribose, thiobarbituric acid (TBA), sodium nitroprusside, N-(1-Naphthyl) ethylenediamine dihydrochloride, potassium hexacyanoferrate $\left(\mathrm{K}_{3} \mathrm{Fe}(\mathrm{CN})_{6}\right)$, trichloroacetic acid (TCA), ferric chloride were procured from SRL Chemicals, India. All the other reagents and solvents were of analytical grade. 


\section{Plant materials}

Gall induced leaves of $P$. integerrima were collected and authenticated By Dr. S. Sundararajan at Center for Advanced Studies in Biology (CASB), Jain University, Bangalore, India, and a voucher specimen (JURUV-78) was kept for conservation in the herbarium. The galls were cleaned with distilled water, dried and crushed into fine powder by using electric grinder.

\section{Preparation of extract}

The coarsely powdered gall materials were sequentially extracted with ethanol and water in Soxhlet apparatus for $24 \mathrm{~h}$. The extracts were evaporated $\left(50^{\circ} \mathrm{C}\right)$ to dryness under reduced pressure using a Rotavapor (BuchiFlawil, Switzerland) and appropiate amount of the residue was used for the antioxidant assays.

\section{Phytochemical analysis}

The preliminary qualitative phytochemical analyses of carbohydrates, alkaloids, saponins, phenolic and tannins, flavonoids, fixed oils and fats, glycosides, phytosterols and triterpenoids in the extracts were carried out using the standard methods as described earlier (Harborne, 1984; Trease and Evans, 1989; Kokate et al., 1998; Khandelwal, 2005; Shrestha et al., 2013, 2014; Eshwarappa et al., 2014; Eshwarappa et al., 2015).

\section{Determination of total phenolic content}

The total phenolics were estimated in the P. integerrima leaf gall extracts (ethanol and aqueous) using Folin-Ciocalteau (FC) reagent method (Kaur and Kapoor, 2002), employing gallic acid as standard. Briefly, $200 \mu \mathrm{l}$ of both ethanol and aqueous extracts $(2 \mathrm{mg} /$ $\mathrm{ml}$ ) were made up to $3 \mathrm{ml}$ with distilled water and then mixed thoroughly with $0.5 \mathrm{ml}$ of Folin-Ciocalteu (FC) reagent. After mixing for $3 \mathrm{~min}, 2 \mathrm{ml}$ of $20 \%$ of sodium carbonate $(\mathrm{w} / \mathrm{v})$ was added and allowed to stand for a further $60 \mathrm{~min}$ in the dark. The absorbance of the reaction mixtures was measured at $650 \mathrm{~nm}$ (Shimadzu, Japan), and the results were expressed as mg of gallic acid equivalent (GAE)/g of dry weight.

\section{Determination of total flavonoid content}

Total flavonoid content of both extracts was determined using the aluminium chloride colorimetric method as described by Chang et al. (2002). In brief, $50 \mu \mathrm{l}$ of ethanol and aqueous extracts $(2 \mathrm{mg} / \mathrm{ml})$ were made up to $1 \mathrm{ml}$ with ethanol, then mixed with $4 \mathrm{ml}$ of distilled water and subsequently with $0.3 \mathrm{ml}$ of $5 \%$ $\mathrm{NaNO}_{2}$ solution. After $5 \mathrm{~min}$ of incubation, $0.3 \mathrm{ml}$ of $10 \% \mathrm{AlCl}_{3}$ solution was added and then allowed to stand for $6 \mathrm{~min}$, which was followed by adding $2 \mathrm{ml}$ of $1 \mathrm{M} \mathrm{NaOH}$ solution to the mixture. Further, water was added to the mixture to bring the final volume to $10 \mathrm{ml}$ and the mixture was allowed to stand for 15 min. The absorbance was measured at $510 \mathrm{~nm}$ (Shimadzu, Japan). Total flavonoid content was calculated as quercetin from a calibration curve. The calibration curve was prepared by preparing quercetin solutions at concentrations 12.5 to $100 \mathrm{mg} \cdot \mathrm{ml}^{-1}$ in ethanol. The result was expressed as $\mathrm{mg}$ quercetin equivalent (QUE)/g of dry weight.

\section{DPPH free radical scavenging activity (DPPH)}

Quantitative measurement of radical scavenging properties of $P$. integerrima leaf gall extracts was carried out according to the method of Blois (1958). Briefly, $0.1 \mathrm{mM}$ solution of 2,2-diphenyl-1-picryl-hydrazyl $\left(\mathrm{DPPH}^{*}\right)$ in ethanol was prepared and $1 \mathrm{ml}$ of this solution was added to $3 \mathrm{ml}$ of the both ethanol and aqueous extracts at various concentrations $(0-100 \mu \mathrm{g} / \mathrm{mL})$ and ascorbic acid was used as a positive control. After incubating the mixture for $30 \mathrm{~min}$ in the dark, the discoloration was measured at $517 \mathrm{~nm}$ (Shimadzu, Japan). The capacity to scavenge the $\mathrm{DPPH}^{*}$ radical was calculated and expressed as percent inhibition using the following equation:

\section{I, $\%=$ (absorbance of control - absorbance of test $/$ absorbance of control) $\times 100$}

The $\mathrm{IC}_{50}$ values (concentration of sample required to scavenge $50 \%$ of free radicals) were calculated from the regression equation prepared from the different concentrations of both ethanol and aqueous extracts.

\section{Hydroxyl radicals scavenging activity}

Quantitative measurement of hydroxyl radical scavenging properties of $P$. integerrima leaf gall extracts was carried out by measuring the competition between deoxyribose and the extracts for hydroxyl radicals generated from the $\mathrm{Fe}^{3+} /$ Ascorbate/EDTA $/ \mathrm{H}_{2} \mathrm{O}_{2}$ system (Halliwell et al., 1988). Briefly, P. integerrima leaf gall extracts (ethanol and aqueous) at various concentrations $(0-100 \mu \mathrm{g} / \mathrm{mL})$ was mixed with the reaction mixture 
containing $0.1 \mathrm{ml}$ of $3.0 \mathrm{mM}$ deoxyribose, $0.5 \mathrm{ml}$ of $\mathrm{FeCl}_{3}(0.1 \mathrm{mM}), 0.5 \mathrm{ml}$ of EDTA $(0.1 \mathrm{mM}), 0.5 \mathrm{ml}$ of ascorbic acid $(0.1 \mathrm{mM}), 0.5 \mathrm{ml}$ of $\mathrm{H}_{2} \mathrm{O}_{2}(1 \mathrm{mM})$ and $0.8 \mathrm{ml}$ of phosphate buffer $(20 \mathrm{mM}, \mathrm{pH} 7.4)$, made up to final volume of $3.0 \mathrm{ml}$. The reaction mixture was incubated at $37^{\circ} \mathrm{C}$ for $1 \mathrm{~h}$ and $1 \mathrm{ml}$ portion of the incubated mixture was mixed with $1 \mathrm{ml}$ of trichloroacetic acid $(10 \%)$ and $1.0 \mathrm{ml}$ of thiobarbituric acid $(0.5 \%)$ to develop pink chromogen that is measured at $532 \mathrm{~nm}$ (Shimadzu, Japan). The hydroxyl radical scavenging capacity was calculated and expressed as \% inhibition of deoxyribose degradation using following equation:

$$
\mathrm{I}, \%=(\text { absorbance of control }- \text { absorbance of test } /
$$$$
\text { absorbance of control) } \times 100
$$

The $\mathrm{IC}_{50}$ values (concentration of sample required to scavenge $50 \%$ of free radicals) were calculated from the regression equation prepared from the different concentrations of both ethanol and aqueous extracts.

Ferric reducing/antioxidant power activity (FRAP) Ferric reducing/antioxidant power (FRAP) was determined following the method reported by Zhao et al. (2008). P. integerrima leaf gall extracts (ethanol and aqueous) at various concentrations $(0-250 \mu \mathrm{g} / \mathrm{mL})$ was mixed with $2.5 \mathrm{ml}$ of $200 \mathrm{mM}$ phosphate buffer (pH 6.6) and $2.5 \mathrm{ml}$ of potassium ferricyanide (1\%) and were incubated at $50^{\circ} \mathrm{C}$ for $20 \mathrm{~min}$. To the incubated mixtures $2.5 \mathrm{ml}$ of $10 \%$ trichloroacetic acid was added and the tubes were centrifuged at 10,000 rpm for $10 \mathrm{~min}$. Further, five milliliters of the upper layer of the solution was mixed with $5.0 \mathrm{ml}$ distilled water and $1 \mathrm{ml}$ of $0.1 \%$ ferric chloride and absorbance of the reaction mixtures was measured at $700 \mathrm{~nm}$ (Shimadzu, Japan).

\section{Statistical analysis}

Statistical analysis was done using SPSS (Windows version 10.0.1; SPSS Inc., Chicago, IL) using a oneway Student's t-test; ${ }^{*} \mathrm{p}<0.05$ was considered as statistically significant, when comparing with relevant controls. All results refer to mean $\pm \mathrm{SD}$.

\section{RESULTS AND DISCUSSION}

Antioxidant therapy has gained an utmost importance in the treatment of several metabolic disorders, where free radicals are implicated (Halliwell, 1997; Shrestha et al., 2013; Shrestha et al., 2014; Eshwarappa et al., 2014; Eshwarappa et al., 2015). Globally, a large number of researchers have aimed at identifying medicinal plants for their potent antioxidant properties to be implicated in metabolic disorders (Auddy et al., 2003; Shrestha et al., 2013; Shrestha et al., 2014; Eshwarappa et al., 2014; Eshwarappa et al., 2015). In agreement with this assumption, the present studies evaluates the antioxidant potential of the aqueous and ethanol extracts of leaf galls of $P$. integerrima and more over, its phytochemical constituents are determined. Firstly, the qualitative presence of phenolics, tannins, flavonoids, polysterols, triterpenoids, saponins and carbohydrates were identified in both aqueous and ethanol extracts and alkaloids were found only in the aqueous extract of leaf galls of $P$. integerrima (Table 1). The antioxidant activities of plant/herb extracts are often explained by their total phenolic and flavonoid contents. The total amount of phenolic and flavonoid content of aqueous and ethanol extracts of leaf galls of $P$. integerrima is summarized in Table 2. The results obtained indicate that in comparison to the aqueous extract the ethanolic extract had the highest total phenolic and flavonoid content at $234 \pm 2.4 \mathrm{mg}$ of GAE/g d.w. and 95.5 $\pm 3.2 \mathrm{mg}$ of QUE/g d.w., respectively (Table 2). These results show that the ethanolic extract possessed significant activity in releasing most of the secondary

Table 1. Phytochemical evaluation of $P$. integerrima leaf gall extracts

\begin{tabular}{lcc}
\hline \multicolumn{1}{c}{$\begin{array}{c}\text { Phytochemical } \\
\text { analysis }\end{array}$} & $\begin{array}{c}\text { Ethanolic extract } \\
\text { of P. integerrima }\end{array}$ & $\begin{array}{c}\text { Aqueous extract } \\
\text { of P. integerrima }\end{array}$ \\
\hline $\begin{array}{l}\text { Phenolics } \\
\text { and tannins }\end{array}$ & + & + \\
Flavonoids & + & + \\
$\begin{array}{l}\text { Phytosterols } \\
\text { and triterpenoids }\end{array}$ & + & + \\
Alkaloids & + & - \\
Saponins & + & + \\
Carbohydrates & + & + \\
Glycosides & - & - \\
Fixed oils and fats & - & - \\
\end{tabular}

+- indicates present, -- indicates absent. 
Table 2. Total phenolic and total flavonoid content of $P$. integerrima leaf gall extracts

\begin{tabular}{lcc}
\hline Gall extracts & $\begin{array}{c}\text { Total phenolic } \\
\text { mg of GAE/g } \\
\text { d.w. }\end{array}$ & $\begin{array}{c}\text { Total flavonoids } \\
\text { mg of QUE/g } \\
\text { d.w. }\end{array}$ \\
\hline Aqueous extract & $182 \pm 3.4$ & $70 \pm 2.2$ \\
Ethanolic extract & $234 \pm 2.4$ & $95.5 \pm 3.2$ \\
\hline
\end{tabular}

Each value is expressed as mean $\pm \mathrm{SD}(n=4)$.

metabolites from leave galls of $P$. integerrima. This may be due to the fact that phenolic and flavonoid compounds are often extracted in higher amounts by using polar solvents such as aqueous ethanol/ethanol (Sultana et al., 2007; Shrestha et al., 2013; Shrestha et al., 2014; Eshwarappa et al., 2014; Eshwarappa et al., 2015). It is reported that differences in the polarity of the extracting solvents could result, in a wide variation, in the polyphenolic and flavonoid contents of the extract (Choi et al., 2007; Shrestha et al., 2013; Shrestha et al., 2014; Eshwarappa et al., 2014; Eshwarappa et al., 2015). Phenolic antioxidants are products of secondary metabolism in plants, and their antioxidant activity is mainly due to their redox properties and chemical structure, which can play an important role in chelating transitional metals and scavenging free radicals (Mohamed et al., 2010; Eshwarappa et al., 2014; Eshwarappa et al., 2015). Similarly, the mechanisms of action of flavonoids are also through scavenging or chelating processes (Kessler et al., 2003; Eshwarappa et al., 2014; Eshwarappa et al., 2015). In addition, compounds such as flavonoids, which contain hydroxyl functional groups, are responsible for the antioxidant effects of plants (Das and Pereira, 1990; Eshwarappa et al., 2014; Eshwarappa et al., 2015).

The higher amount of total phenolic and flavonoid content of leaf galls extracts of $P$. integerrima suggests that it possesses high antioxidant activity. DPPH is a stable free radical, which has been widely accepted as a tool for estimating free radical-scavenging activities of antioxidants (Naik et al., 2003). The percentage inhibition of DPPH in the presence of aqueous and ethanol extracts of $P$. integerrima are shown in Figure 1. The aqueous extract exhibited an inhibition of $54 \%$, whereas ethanol extract showed a $86 \%$ inhibition at the concentration of $100 \mu \mathrm{g} / \mathrm{ml}$ used. Therefore, in

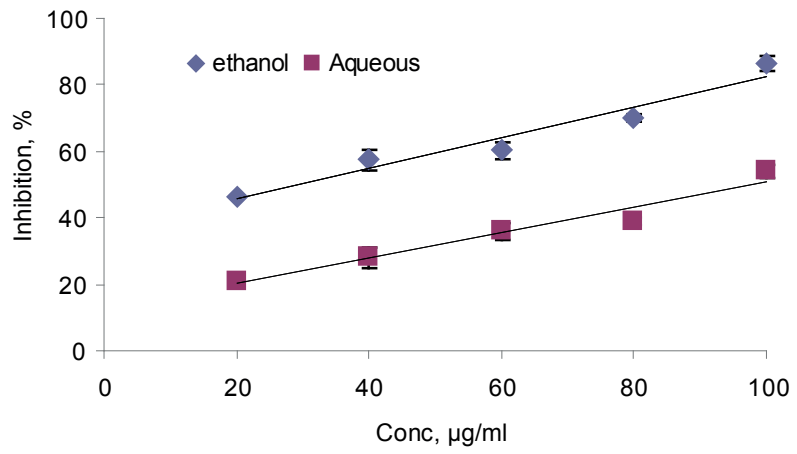

Fig. 1. Free radical scavenging activity of aqueous and ethanol extract of leaf galls of $P$. integerrima. Ascorbic acid was used as a positive control. Activity was measured by the scavenging of DPPH radicals and expressed as \% inhibition. Each value is expressed as the mean \pm standard deviation $(n=4)$

the present study the antioxidant activity of alcoholic extract was $30 \%$ higher as compared to the aqueous extract. $\mathrm{The}^{\mathrm{IC}} \mathrm{I}_{50}$ values of aqueous and ethanolic extracts were found to be $97.15 \pm 06$ and $29.64 \pm 02$, respectively (Table 3). The results indicate that the ethanol extract pocessed potent DPPH scavenging activities. These results indicate that the ethanol extracts have a significant and noticeable effect on scavenging free radicals by DPPH method and this can be directly associated to the high phenolic constituents present in the extract (Table 2). Phenolic antioxidants are products of secondary metabolism in plants, and the antioxidant activity is mainly due to their redox properties and chemical structure, which can play an important role in chelating transitional metals, inhibiting lipoxygenase and scavenging free radicals (Decker, 1997; Eshwarappa et al.,

Table 3. $\mathrm{IC}_{50}$ values of $P$. integerrima gall extracts and standard ascorbic acid

\begin{tabular}{ccc}
\hline \multirow{2}{*}{$\begin{array}{c}\text { P. integerrima } \\
\text { gall extract }\end{array}$} & \multicolumn{2}{c}{$\mathrm{IC}_{50}$ values, $\mu \mathrm{g} / \mathrm{ml}$} \\
\cline { 2 - 3 } & $\mathrm{DPPH}$ assay & $\begin{array}{c}\text { Hydroxyl radical } \\
\text { scavenging assay }\end{array}$ \\
\hline Aqueous extract & $97.15 \pm 1.06$ & $80 \pm 2.06$ \\
Ethanolic extract & $29.64 \pm 1.02$ & $54.03 \pm 1.02$ \\
Ascorbic acid & $12.93 \pm 2.03$ & $24.28 \pm 2.06$ \\
\hline
\end{tabular}

Each value is expressed as mean $\pm \mathrm{SD}(n=4)$. 
2014; Eshwarappa et al., 2015). Phenolic compounds are also effective hydrogen donors, which makes them good antioxidants (Rice-Evans et al., 1995; Eshwarappa et al., 2014; Eshwarappa et al., 2015).

The highly reactive hydroxyl radicals can cause oxidative damage to DNA, lipids and proteins. The higher amount of total phenolic and flavonoid content of leaf galls extracts of $P$. integerrima suggested that it possesses high hydroxyl scavenging activity. The hydroxyl radical scavenging activity of leaf galls of $P$. integerrima is as shown in Figure 2. The percentage of inhibition of aqueous and ethanol extract of $P$. integerrima gall was found to be at $74.38 \%$ and $93.75 \%$, respectively at a concentration of $100 \mu \mathrm{g} / \mathrm{ml}$ used.

Therefore, in the present study the hydroxyl radical scavenging activity of alcoholic extract was $20 \%$ higher as compared to the aqueous extract leaf gall extract of $P$. integerrima. $\mathrm{The}^{\mathrm{IC}} \mathrm{I}_{50}$ values of aqueous and ethanolic extract were found to be $80 \pm 06 \mu \mathrm{g} / \mathrm{ml}$ and $54.03 \pm 02 \mu \mathrm{g} / \mathrm{ml}$, respectively. The results indicate that the ethanol extract possessed significant and potent hydroxyl radical scavenging activities which can be related to the high phenolic constituents present (Table 2). As explained earlier, the antioxidant activities of plant/ herb extracts are often explained by their total phenolic and flavonoid contents. The results also suggest that there was a direct association of hydroxyl scavenging activities with that of total phenolic and flavonoid content in the leaf gall extracts of $P$. integerrima.

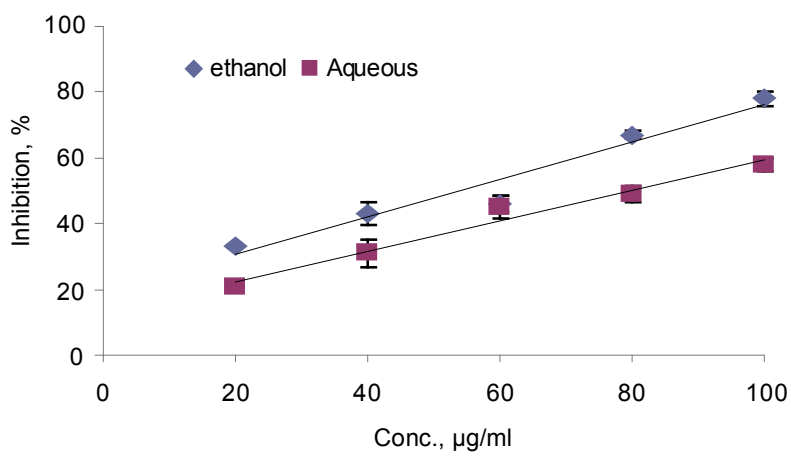

Fig. 2. Hydroxyl radical scavenging activity of aqueous and ethanol extract of leaf galls of $P$. integerrima. Ascorbic acid was used as a positive control. Activity was measured and expressed as \% inhibition. Each value is expressed as the mean \pm standard deviation $(n=4)$
The reducing capacity of compounds or extracts may serve as a significant indicator of their potential antioxidant activities. The presence of a reductant, such as the antioxidant substances in plant extracts, causes the reduction of $\mathrm{Fe}^{3+}$ ferricyanide complex to the ferrous form, $\mathrm{Fe}^{2+}$. The reduction capabilities of aqueous and ethanol extracts of leaf galls of $P$. integerrima is indicated as in Figure 3. In comparison with the aqueous extract, the ethanol extract had better reducing power at a concentration of $250 \mu \mathrm{g} / \mathrm{mL}$ (Fig. 3). The ferric reducing power of leaf galls of $P$. integerrima may be attributed to the high phenolic and flavonoid contents of the extracts (Table 2). The ability to reduce Fe (III) may be attributed to the hydrogen donation from phenolic compound (Shimada et al., 1992; Eshwarappa et al., 2014; Eshwarappa et al., 2015), which is related to the presence of a reducing agent (Duh, 1998). In addition, the number and position of hydroxyl group of phenolic compounds also govern their antioxidant activity (Rice-Evans et al., 1995; Eshwarappa et al., 2014; Eshwarappa et al., 2015).

In this study, it was observed that there was a direct asoosciation of hydroxyl scavenging activities with that of total phenolic and flavonoid content in the leaf gall extracts of $P$. integerrima, tannins, and flavonoids. Monoterpenes, triterpenoids, sterol, dihydromalvalic acid, flavonoids, essential oils, anthocyanins and other phenolic constituents have been reported from the different parts of Pistacia species (Ahmed et al., 2010, 2011; Bozorgi et al., 2013). Phenolics, Fatty

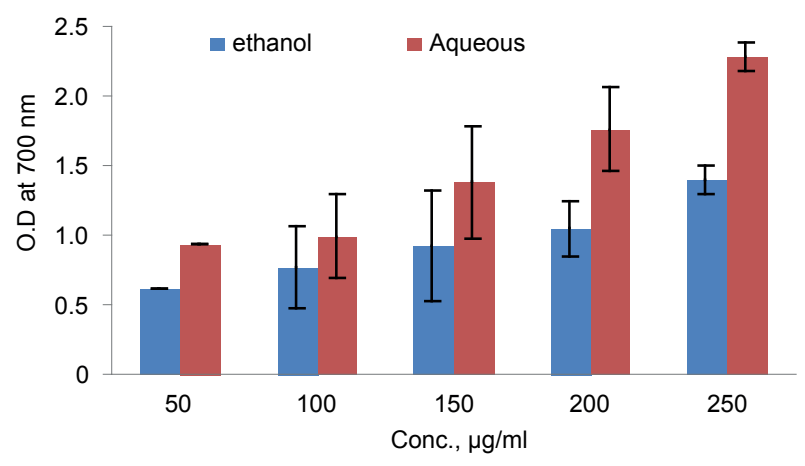

Fig. 3. Ferric reducing power of aqueous and ethanol extract of leaf gall of $P$. integerrima. Activity is expressed at absorbance at $700 \mathrm{~nm}$. Each value is expressed as the mean \pm standard deviation $(n=4)$ 
ester, ketoalcohol and triterpenic acid has been reported from galls of P. integerrima (Ahmed et al., 2010, 2011). The results given in this investigation showed that the phenolic and flavonoid content was higher in polar extracts (ethanol) and subsequently a higher antioxidant potential. Therefore, it seems clear that the presence of polar phenolics is fundamental in the evaluation of free radical-scavenging activity (Al-Reza et al., 2009; Eshwarappa et al., 2014; Eshwarappa et al., 2015). The activity of antioxidant has been assigned to various mechanisms such as prevention of chain initiation, binding of transition-metal ion catalysts, decomposition of peroxides, prevention of continued hydrogen abstraction, reductive capacity and radical scavenging (Yildirim et al., 2000; Eshwarappa et al., 2014; Eshwarappa et al., 2015). These observations confirm the folklore use of $P$. integerrima leaf gall extracts as a natural antioxidant and justify the ethnobotanical approach in the search for novel bioactive compounds with functional nutraceutical properties.

\section{CONCLUSION}

This study demonstrates the potent antioxidant activities of $P$. integerrima leaf gall extracts. The findings of this study support the view that the extracts obtained using a high polarity solvent (ethanol) were considerably more effective for extracting radical scavengers molecules. Further, it was observed that there was a strong association between the higher antioxidant activities with that of higher total phenolic and flavonoid content in the ethanolic leaf gall extracts of $P$. integerrima. Further, the results of this study confirm the folklore use of $P$. integerrima leaf gall extracts as a natural antioxidant and justify the ethnobotanical approach in the search for novel bioactive compounds. Further, the results support the use of gall extracts as promising sources of potential antioxidants that may be effective as preventive agents in the pathogenesis of some metabolic diseases. Therefore, the results encourage the use of $P$. integerrima leaf gall extracts for medicinal health, functional food and nutraceuticals applications, due to their antioxidant properties. Future work will be interesting to learn the chemical composition and better understand the mechanism of action of the antioxidants present in the extract for development as drug for therapeutic application.

\section{ACKNOWLEDGEMENTS}

We acknowledge Dr. R. Chenraj Jain, President, Jain University Trust., Dr. N Sundararajan, Vice Chancellor, Jain University and Prof. K.S. Shantamani, Chief Mentor, Jain University, Bangalore for their kind support and encouragement and for providing facilities for carrying out this work. DBL thank Jain University for their constant encouragement provided to proceed in research activities.

\section{REFERENCES}

Ahmed, S., Ali, M., Ansari, S. H. (2011). Phenolic constituents from the galls of Pistacia integerrima stewart. Ind. J. Chem., 50B, 115-118.

Ahmed, S., Ali, M., Ansari, S. H., Ahmed, F. (2010). Phytoconstituents from the galls of Pistacia integerrema stewart. J. Saudi Chem. Soc., 14, 409-412.

Al-Reza, S. M., Rahman, A., Kang, S. C. (2009). Chemical composition and inhibitory effect of essential oil and organic extracts of Cestrum nocturnum L. on food-borne pathogens. Int. J. Food Sci. Technol., 44, 1176-1182.

Auddy, B., Ferreira, F., Blasina, L., Lafon, F., Arredondo, F., ..., Mukherjee, B. (2003). Screening of antioxidant activity of three Indian medicinal plants, traditionally used for the management of neurodegenerative diseases. J. Ethnopharm., 84, 131-138.

Blois, M. S. (1958). Antioxidants determination by the use of a stable free radical. Nature, 181, 1199-1200.

Bozorgi, M., Memariani, Z., Mobli, M., Surmaghi, M. H. S., Shams-Ardekani, M. R., Rahimi, R. (2013). Five Pistacia species ( $P$. vera, $P$. atlantica, $P$. terebinthus, $P$. khin$j u k$, and $P$. lentiscus): A review of their traditional uses, phytochemistry, and pharmacology. Sci. World J., DOI: 10.1155/2013/219815.

Chang, C., Yang, M., Wen, H., Chern, J. (2002). Estimation of total flavonoid content in propolis by two complementary colorimetric methods. J. Food Drug. Anal., 10(3), 178-182.

Choi, Y., Jeong, H. S., Lee, J. (2007). Antioxidant activity of methanolethanolic extracts from some grains consumed in Korea. Food Chem., 103, 130-138.

CSIR (1976). The wealth of India. A dictionary of Indian raw materials and industrial products (pp. 120-121). New Delhi: Council of Scientific and Industrial Research.

Das, N. P., Pereira, T. A. (1990). Effects of flavanoids on thermal autooxidation of palm oil: structure activity relationship. J. Am. Oil Chem. Soc., 67, 255-258.

Decker, E. A. (1997). Phenolics: prooxidants or antioxidants? Nutr. Rev., 55, 396-407. 
Eshwarappa, R. S. B., Lakshmikantha, R. Y., Subaramaihha, S. R., Subbaiah, S. G. P., Surendranath, A. R., Dhananjaya, B. L. (2015). Antioxidant activity of insect gall extracts of Pistacia integerrima. Acta Sci. Pol. Technol. Aliment., 14(4), 367-374. DOI: 10.17306/J. AFS.2015.4.36

Duh, P. D. (1998). Antioxidant activity of Budrock (Arctium laooa Linn.) its scavenging effect on free radical and active oxygen. J. Am. Oil Chem. Soc., 75, 455-461.

Eshwarappa, R. S., Iyer, R. S., Subbaramaiah, S. R., Richard, S. A., Dhananjaya, B. L., (2014). Antioxidant activities of Syzygium cumini leaf gall extracts. BioImpacts, 4(2), 101-107.

Eshwarappa, R. S. B., Ramachandra, Y. L., Subaramaihha, S. R., Subbaiah, S. G. B., Austin, R. S., Dhananjaya, B. L. (2015). Antioxidant activities of leaf galls extracts of Terminalia chebula (Gaertn.) Retz. (Combretaceae). Acta Sci. Pol. Technol. Aliment., 14(2), 97-105.

Gossell-Williams, M., Simon, O. R., West, M. E. (2006). The past and present use of plants for medicines. West Indian. Med. J., 55, 217-218.

Gunakari Ayurvediy Aushadhe (1968). Pune: Ayurveda Rasashala.

Halliwell, B. (1997). Antioxidants and human disease: a general introduction. Nut. Rev., 55(1), 44-52.

Halliwell, B., Grootveld, M., Gutteridge, J. M. C. (1988). Methods for the measurement of hydroxyl radicals in biochemical systems: Deoxyribose degradation and aromatic hydroxylation. Methods of biochemical analysis. John Wiley, 59-90.

Harborne, J. J. (1984). Phytochemical methods: A guide to modern techniques of plant analysis. New York: Chapman and Hall.

Kaur, C., Kapoor, H. C. (2002). Anti-oxidant activity and total phenolic content of some Asian vegetables. Int. J. Food Sci. Technol., 37, 153-161.

Kessler, M., Ubeaud, G., Jung, L. (2003). Anti- and pro-oxidant activity of rutin and quercetin derivatives. J. Pharm. Pharmacol., 55, 131-142.

Khandelwal, K. R. (2005). Practical pharmacognosy: Techniques and experiments (pp. 149-156). Pune: Nirali Prakashan.

Kirthikar, K. R., Basu, B. D. (1935). Indian medicinal plants. Vol. 2. Allahabad: Lalit Mohan Basu.

Kokate, C. K., Purohit, A. P., Gokhale, S. B. (1998). Pharmacognosy (pp. 106-114). Pune: Nirali Prakashan.

Kottakkal, A. V. S. (1995). Indian medicinal plants. Vol. 4. Kottakkal: Orient Longman.

Mohamed, A. A., Khalil, A. A., El-Beltagi, H. E. S. (2010). Antioxidant and antimicrobial properties of kaff maryam (Anastatica hierochuntica) and doum palm (Hyphaene thebaica). Grasas Aceites, 61(1), 67-75.

Nadkarni, K. M. (1976). Indian materia medica (pp. 10621063). Mumbai: Popular Prakashan.
Naik, G. H., Priyadarsini, K. I., Satav, J. G., Banavalikar, M. M., Sohani, D. P., Biyani, M. K., Mohan, H. (2003). Comparative antioxidant activity of individual herbal components used in ayurvedic medicine. Phytochemistry, 63, 97-104.

Rice-Evans, C. A., Miller, N. J., Bolwell, P. G., Bramley, P. M., Pridham, J. B. (1995). The relative antioxidant activities of plant-derived polyphenolic flavonoids. Free Rad. Res., 23, 375-383.

Shantha, T. R., Shetty, J. K. P., Yoganarasinhan, S. N., Sudha, R. (1991). Farmocognostical studies on South Indian market sample of Karkatasringi - Terminalia chebulla (Gaertn. leaf gall). Anc. Sci. Life, 11, 16-22.

Shimada, K., Fujikawa, K., Yahara, K., Nakamura, T. (1992). Antioxidative properties of xanthan on the autoxidation of soyabean oil in cyclodextrin emulsion. J. Agric. Food Chem., 40, 945-948.

Shrestha, S., Kaushik, V. S., Eshwarappa, R. S., Subaramaihha, S. R., Ramanna, L. M., Lakkappa, D. B. (2014). Pharmacognostic studies of insect gall of Quercus infectoria Olivier (Fagaceae). Asian Pac. J. Trop. Biomed., 4(1), 35-39.

Shrestha, S., Subaramaihha, S. R., Subbaiah, S. G., Eshwarappa, R. S., Lakkappa, D. B. (2013). Evaluating the antimicrobial activity of methanolethanolic extract of rhus succedanea leaf gall. Bioimpacts, 3(4), 195-198.

Sukh, D. (1997). Ethanotherapeutics and modern drug development. The potential of Ayurveda. Curr. Sci., 73, 909-928.

Sultana, B., Anwar, F., Przybylski, R. (2007). Antioxidant activity of phenolic components present in barks of barks of Azadirachta indica, Terminalia arjuna, Acacia nilotica, and Eugenia jambolana Lam. trees. Food Chem., 104, 1106-1114.

Trease, G. E., Evans, W. C. (1989). Pharmacognosy. Delhi: ELBS Publication.

Yildirim, A., Mavi, A., Oktay, M., Kara, A. A., Algur, O. F., Bilaloglu, V. (2000). Comparison of antioxidant and antimicrobial activities of Tilia (Tilia argentea Desf. ex DC.), Sage (Salvia triloba L.), and Black Tea (Camellia sinensis) extracts. J. Agric. Food Chem., 48, 5030-5034.

Zhao, H., Fan, W., Dong, J., Lu, J., Chen, J., Shan, L., ..., Kong, W. (2008). Evaluation of antioxidant activities and total phenolic contents of typical malting barley varieties. Food Chem., 107, 296-304. DOI: 10.1016/j. foodchem.2007.08.018

Accepted for print - Zaakceptowano do druku: 14.09.2015

Eshwarappa, R. S. B., Lakshmikantha, R. Y., Subaramaihha, S. R., Subbaiah, S. G. P., Surendranath, A. R., Dhananjaya, B. L. (2015). Antioxidant activity of insect gall extracts of Pistacia integerrima. Acta Sci. Pol. Technol. Aliment., 14(4), 367-374. DOI: 10.17306/J. AFS.2015.4.36 